\title{
Recognition, assessment and treatment of social anxiety disorder: summary of NICE guidance
}

Article

Published Version

Pilling, S., Mayo-Wilson, E., Mavranezouli, I., Kew, K. M., Taylor, C., Clark, D. M., Afgan, S., Anigbogu, B., Armstrong, P., Bennett, M., Cartwright-Hatton, S., Creswell, C., Dix, M., Hanlon, N., Leggett, K., Malizia, A. L., Roberts, J., Satrettin, K., Stephens, G., Stockton, S. and Stopa, L. (2013)

Recognition, assessment and treatment of social anxiety disorder: summary of NICE guidance. British Medical Journal, 346. f2541. ISSN 1468-5833 doi:

https://doi.org/10.1136/bmj.f2541 Available at https://centaur.reading.ac.uk/40688/

It is advisable to refer to the publisher's version if you intend to cite from the work. See Guidance on citing.

To link to this article DOI: http://dx.doi.org/10.1136/bmj.f2541

Publisher: BMJ Publishing Group Ltd

All outputs in CentAUR are protected by Intellectual Property Rights law, including copyright law. Copyright and IPR is retained by the creators or other copyright holders. Terms and conditions for use of this material are defined in the End User Agreement. 


\section{www.reading.ac.uk/centaur}

\section{CentAUR}

Central Archive at the University of Reading

Reading's research outputs online 


\title{
Recognition, assessment and treatment of social anxiety disorder: summary of NICE guidance
}

\author{
Stephen Pilling director, professor ${ }^{123}$, Evan Mayo-Wilson senior research associate ${ }^{123}$, Ifigeneia \\ Mavranezouli senior research fellow in health economics ${ }^{123}$, Kayleigh Kew systematic reviewer ${ }^{4}$, \\ Clare Taylor senior editor ${ }^{5}$, David M Clark professor ${ }^{6}$, On behalf of the Guideline Development \\ Group
}

${ }^{1}$ National Collaborating Centre for Mental Health, University College London, London WC1E 7HB, UK; ${ }^{2}$ Centre for Outcomes Research and Effectiveness, University College London, London WC1E 7HB, UK; ${ }^{3}$ Research Department of Clinical, Educational and Health Psychology, University College London, London WC1E 7HB, UK; ${ }^{4}$ Cochrane Airways Group, Population Health Sciences and Education, St George's, University of London, London SW17 ORE, UK; ${ }^{5}$ National Collaborating Centre for Mental Health, Royal College of Psychiatrists, London E1 8AA, UK; ${ }^{6}$ Department of Experimental Psychology, University of Oxford, Oxford OX1 3UD, UK

This is one of a series of $B M J$ summaries of new guidelines based on the best available evidence; they highlight important recommendations for clinical practice, especially where uncertainty or controversy exists.

Social anxiety disorder is one of the most persistent and common of the anxiety disorders, with lifetime prevalence rates in Europe of $6.7 \%$ (range $3.9-13.7 \%$ ). ${ }^{1}$ It often coexists with depression, substance use disorder, generalised anxiety disorder, panic disorder, and post-traumatic stress disorder. ${ }^{2}$ It can severely impair a person's daily functioning by impeding the formation of relationships, reducing quality of life, and negatively affecting performance at work or school. Despite this, and the fact that effective treatments exist, only about half of people with this condition seek treatment, many after waiting $10-15$ years. $^{3}$ Although about $40 \%$ of those who develop the condition in childhood or adolescence recover before adulthood, ${ }^{4}$ for many the disorder persists into adulthood, with the chance of spontaneous recovery then limited compared with other mental health problems.

This article summarises the most recent recommendations from the National Institute for Health and Care Excellence (NICE) on recognising, assessing, and treating social anxiety disorder in children, young people, and adults. ${ }^{5}$

\section{Recommendations}

NICE recommendations are based on systematic reviews of the best available evidence and explicit consideration of cost effectiveness. When minimal evidence is available, recommendations are based on the Guideline Development Group's experience and opinion of what constitutes good practice. Evidence levels for the recommendations are given in italic in square brackets.

\section{Principles for working with all people with social anxiety disorder}

- When a person is first offered an appointment, provide clear information in a letter about:

-Where to go on arrival and where they can wait (offer the use of a private waiting area or the option to wait elsewhere-for example, outside the service's premises)

-Location of facilities available at the service (for example, the car park and toilets)

-What will happen and what will not happen during assessment and treatment.

When the person arrives for the appointment, offer to meet them or alert them (for example, by text message) when their appointment is about to begin. [Based on the experience and opinion of the Guideline Development Group (GDG) and on evidence reviewed in two recent NICE guidelines on mental health ${ }^{67}$ ]

- Offer to provide treatment in settings where children and young people and their parents or carers feel most comfortable-for example, at home or in schools or community centres. [Based on the experience and opinion of the $G D G$ ] 


\section{Identification of adults with possible social anxiety disorder}

- Ask the identification questions using the two-item generalised anxiety disorder scale $(\mathrm{GAD}-2)^{8}$ in line with NICE guidance ${ }^{6}$, and if social anxiety disorder is suspected: -Use the three-item mini-social phobia inventory $(\text { Mini-SPIN })^{9}$ or

-Consider asking the following two questions: Do you find yourself avoiding social situations or activities? Are you fearful or embarrassed in social situations?

If the person scores 6 or more on the Mini-SPIN or answers yes to either of the two questions above, refer for or conduct a comprehensive assessment for social anxiety disorder.

[Based on a systematic review of assessment tools and the experience and opinion of the GDG]

\section{Identification of children and young people with possible social anxiety disorder}

Professionals in primary care and education and in community settings should be alert to possible anxiety disorders in children and young people, particularly those who avoid school, social or group activities, or talking in social situations, or are irritable, excessively shy, or overly reliant on parents or carers. Consider asking the child or young person (or their parents or carers) about their feelings of anxiety, fear, avoidance, distress, and associated behaviours, to help establish if social anxiety disorder is present, using the following statement and questions:

"Sometimes people get very scared when they have to do things with other people, especially people they don't know. They might worry about doing things with other people watching. They might get scared that they will do something silly or that people will make fun of them. They might not want to do these things or, if they have to do them, they might get very upset or cross." Then ask:

-"Do you/does your child get scared about doing things with other people, like talking, eating, going to parties, or other things at school or with friends?"

-"Do you/does your child find it difficult to do things when other people are watching, like playing sport, being in plays or concerts, asking or answering questions, reading aloud, or giving talks in class?"

-"Do you/does your child ever feel that you/your child can't do these things or tries to get out of them?"

[Based on the experience and opinion of the GDG]

If the child or young person or parents or carers answer "yes" to one or more of the questions consider a comprehensive assessment for social anxiety disorder. [Based on the experience and opinion of the GDG]

\section{Comprehensive assessment for children, young people, and adults}

- Obtain a detailed description of the person's current social anxiety and associated problems and circumstances including:

-Feared and avoided social situations, and what they are afraid might happen in social situations (for example, looking anxious, blushing, sweating, trembling, or appearing boring)

-Anxiety symptoms

-View of self
-Safety seeking behaviours

-Anticipatory and post-event processing

-Occupational, educational, financial, and social circumstances in adults

-Family circumstances and support, friendships and peer groups, educational and social circumstances in children and young people

-Medication, alcohol, and recreational drug use.

[Based on the experience and opinion of the GDG]

\section{Delivering interventions for children, young people, and adults}

All interventions should be delivered by competent practitioners. Psychological interventions should be based on the relevant treatment manual(s), which should guide their structure and duration. Practitioners should consider using competence frameworks developed from the relevant treatment manual(s) and for all interventions should receive regular, high quality, outcome informed supervision; use routine sessional outcome measures; and monitor treatment adherence and practitioner competence (for example, using video and audio recordings, and external audit and scrutiny if appropriate). [Based on a systematic review of assessment tools and the experience and opinion of the GDG]

\section{Interventions for adults with social anxiety disorder}

\section{First line treatment}

- Offer adults individual cognitive behavioural therapy (CBT) that has been specifically developed to treat social anxiety disorder (based on the Clark and Wells model or the Heimberg model $^{5}$ ). [Based on a systematic review, network meta-analysis, and an economic model]

- Do not routinely offer group CBT in preference to individual CBT. Although there is evidence that group CBT is more effective than most other interventions, it is less clinically and cost effective than individual CBT. [Based on a systematic review, network meta-analysis, and an economic model]

\section{Second line treatments}

- For adults who decline CBT and wish to consider another psychological intervention, offer CBT based, supported self help.[Based on a systematic review, network meta-analysis, and an economic model]

- For adults who decline cognitive behavioural interventions and express a preference for a drug intervention, discuss their reasons for declining cognitive behavioural interventions and try to resolve any concerns. [Based on the experience and opinion of the GDG and on a systematic review, network meta-analysis, and an economic model]

- If the person wishes to proceed with a drug intervention, offer a selective serotonin reuptake inhibitor (escitalopram or sertraline). Monitor carefully for adverse reactions. [Based on a systematic review, network meta-analysis, and an economic model]

\section{Third line treatments}

- For adults who decline cognitive behavioural interventions and drug treatment, consider short term, psychodynamic 
psychotherapy specifically developed for social anxiety disorder. However, bear in mind the more limited clinical and cost effectiveness of this intervention. [Based on a systematic review, network meta-analysis, and an economic model]

The components of the recommended psychological therapies for adults can be found in the full NICE guideline. ${ }^{5}$

\section{Interventions for children and young people with social anxiety disorder}

- Offer individual or group CBT focused on social anxiety. Consider involving parents or carers for effective delivery of the intervention, particularly in young children. [Based on a systematic review and meta-analysis]

The components of the recommended psychological therapies for adults can be found in the full NICE guideline. ${ }^{5}$

- Do not routinely offer drug interventions to treat social anxiety disorder in children and young people. [Based on a systematic review and meta-analysis]

\section{Overcoming barriers}

The guideline deals with several potential barriers to people seeking treatment for social anxiety disorder: people may think that the social anxiety is part of their personality and cannot be changed (or, in the case of children, that they will grow out of it); they may fear negative evaluation by healthcare professionals if they disclose their problem; even after presentation, the disorder may not be recognised by healthcare professionals, especially in primary care. ${ }^{10}$ The guideline advises healthcare professionals to be aware of barriers to people seeking treatment, and on how to identify the disorder in all age groups and how services can make themselves more accessible. It also recommends effective treatments and seeks to help commissioners identify the services that should be made available.

The members of the Guideline Development Group were David Clark (chair), Stephen Pilling (facilitator), Evan Mayo-Wilson, Ifigeneia Mavranezouli, Safi Afghan, Benedict Anigbogu, Peter Armstrong, Madeleine Bennett, Sam Cartwright-Hatton, Cathy Creswell, Melanie
Dix, Nick Hanlon, Kayleigh Kew, Katherine Leggett, Andrea Malizia, Jane Roberts, Kate Satrettin, Gareth Stephens, Sarah Stockton, Luisa Stopa, and Clare Taylor.

Contributors: All authors contributed to the conception and drafting of this article and revising it critically. They have all approved this version. $\mathrm{SP}$ is the guarantor.

Competing interests: All authors have completed the Unified Competing Interest form at www.icmje.org/coi_disclosure.pdf (available on request from the corresponding author) and declare: (1) SP, EM-W, IM, KK, and CT had support from the National Collaborating Centre for Mental Health, which was in receipt of funding from NICE, for the submitted work; (2) $\mathrm{DMC}$ developed one of the psychological therapies under consideration so was excluded from discussion of recommendations related to that treatment; (3) no other relationships or activities that could appear to have influenced the submitted work.

Provenance and peer review: Commissioned; not externally peer reviewed.

1 Fehm L, Pélissolo A, Furmark T, Wittchen H-U. Size and burden of social phobia in Europe. Eur Neuropsychopharmacol 2005;15:453-62.

2 Wittchen HU, Fehm L. Epidemiology and natural course of social fears and social phobia. Acta Psychiatr Scand Suppl 2003;417:4-18.

3 Grant BF, Hasin DS, Blanco C, Stinson FS, Chou SP, Goldstein RB, et al. The epidemiology of social anxiety disorder in the United States: results from the National Epidemiologic Survey on Alcohol and Related Conditions. J Clin Psychiatry 2005;11:1351-61.

4 Beesdo-Baum K, Knappe S, Fehm L, Höfler M, Lieb R, Hofmann SG, et al. The natural course of social anxiety disorder among adolescents and young adults. Acta Psychiatr Scand 2012;126:411-25.

5 National Institute for Health and Care Excellence. Social anxiety disorder: recognition, assessment and treatment of social anxiety disorder. (Clinical guideline 159.) 2013. http: //guidance.nice.org.uk/CG159.

6 National Institute for Health and Clinical Excellence. Common mental health disorders: identification and pathways to care. (Clinical guideline 123.) 2011. http://guidance.nice. org.uk/CG123.

7 National Institute for Health and Clinical Excellence. Service user experience in adult mental health: improving the experience of care for people using adult NHS mental health services (Clinical guideline 136.) 2011. http://guidance.nice.org.uk/CG136.

8 Kroenke K, Spitzer RL, Williams JB, Monahan PO, Lowe B. Anxiety disorders in primary care: prevalence, impairment, comorbidity and detection. Ann Intern Med 2007;146:317-25.

9 Connor KM, Kobak KA, Churchill LE, Katzelnick D, Davidson JR. Mini-SPIN: a brief screening assessment for generalized social anxiety disorder. Depression Anxiety 2001;14;137-40.

10 Wittchen $\mathrm{H}-\mathrm{U}$, Jacobi F. Size and burden of mental disorders in Europe-a critical review and appraisal of 27 studies. Eur Neuropsychopharmacol 2005;15:357-76.

Accepted: 16 April 2013

Cite this as: BMJ 2013;346:f2541

(C) BMJ Publishing Group Ltd 2013 


\section{Further information on the guidance}

Factors prompting the development of this guideline include the poor recognition and inadequate assessment of social anxiety disorder and the limited awareness or availability of treatments despite the existence of effective psychological and drug interventions. Social anxiety disorder is under-recognised in primary care,$^{10}$ particularly when it coexists with depression. Often the depressive episode may be identified but the underlying and more persistent social anxiety disorder is not. The early age of onset means that recognition of social anxiety disorder in educational settings is important and may bring early and lasting benefits to children, but it is challenging to achieve this without accurate identification and clear referral pathways.

\section{Methods}

This guideline was developed by the National Collaborating Centre for Mental Health using NICE guideline methods (www.nice.org.uk/ guidelinesmanual). The guideline review process involved comprehensive and systematic literature searches to identify relevant evidence for the clinical and economic reviews, with critical appraisal of the quality of the identified evidence. Results of intervention studies were compared using pairwise and network meta-analysis. Results of the network meta-analysis were used to inform an economic model. A multidisciplinary team of healthcare professionals from psychiatry, psychology, and general practice and service user and carer representatives (forming the GDG) was established to review the evidence and develop the subsequent recommendations. The guideline then went through an external consultation with stakeholders. The GDG considered the stakeholders' comments, reanalysed the data where necessary, and modified the guideline as appropriate.

NICE has produced three different versions of the guideline: a full version; a summary version known as the "NICE guideline"; and a version for children, young people, and adults with social anxiety disorder, their parents and carers, and the public. All these versions, as well as a pathway, are available from the NICE website. Updates of the guideline will be produced as part of NICE's guideline development programme.

Areas for future research

- What methods are effective in improving uptake of and engagement with interventions for adults with social anxiety disorder?

- What is the best way of involving parents in the treatment of children and young people with social anxiety disorder at different stages of development?

- What is the clinical and cost effectiveness of specific CBT for children and young people with social anxiety disorder compared with generic anxiety focused CBT?

- What is the clinical and cost effectiveness of individual and group CBT for children and young people with social anxiety disorder?

- What is the clinical and cost effectiveness of combined psychological and drug interventions compared with either intervention alone in treating adults with social anxiety disorder? 